\title{
Effects of ultraviolet irradiation on photosynthetic pigments in some filamentous cyanobacteria
}

\author{
Victoria Adubea Donkor*, Donat-P. Häder** \\ Institut für Botanik und Pharmazeutische Biologie, Friedrich-Alexander-Universität, Staudtstr. 5, D-91058 Erlangen, Germany
}

\begin{abstract}
The effects of ultraviolet-B irradiation on the cyanobacteria Anabaena variabilis, Oscillatoria tenuis, Nodularia baltica, N. harveyana and Phormidium uncinatum (Baikal and Tübingen strain) indicated that pigmentation and energy transfer to the photosynthetic reaction centers were impaired. Absorption and fluorescence spectra showed photobleaching of photosynthetic pigments, especially in the accessory antenna pigments, with prolonged irradiation. Fluorescence emission and excitation spectra indicated an initial disturbance of energy transfer and subsequent photobleaching of these pigments. Exposure to solar and artificial UV-B irradiation resulted in a very rapid inhibition of photosynthetic oxygen exchange, as compared to photobleaching, including structural changes in the photosynthetic apparatus.
\end{abstract}

KEY WORDS: Absorption spectra - Cyanobacteria - Energy transfer Fluorescence spectra Photobleaching Pigmentation Ultraviolet radiation

\section{INTRODUCTION}

The major wavebands of the solar spectrum exhibit differences in biological effectiveness. The UV-B waveband ( 280 to $315 \mathrm{~nm}$ ) causes damage to organisms (Jagger 1985). The biological effectiveness of UV radiation increases logarithmically with decreasing wavelengths. This increase is primarily due to the increased overlap between the absorption spectra of nucleic acids and proteins as the wavelength decreases (Setlow 1974). The visible radiation waveband between 400 and $700 \mathrm{~nm}$, also referred to as photosynthetic active radiation (PAR), is primarily significant for its role in photosynthesis and plant photomorphogenesis, although it also has significant thermal and photodestructive effects (Tevini \& Häder 1987). Since the action of radiation on biological processes is highly wavelength-dependent, the type of radiation in the environment of the organisms, and the extent to which the organism alters the radiation through e.g. pigmen-

- Present address: Department of Botany, University of Cape Coast, Cape Coast, Ghana

- Addressee for correspondence.

E-mail: dphaeder@biologie.uni-erlangen.de tation, will influence the ultimate effect of radiation on the physiological processes of the organisms.

Recently, with the increase of man-made pollutants such as chlorinated fluorocarbons in the atmosphere, the problem has arisen of the gradual depletion of the ozone layer in the stratosphere, with the resultant increase of UV-B radiation. This increased radiation poses a serious stress factor to all organisms (Setlow 1974, Ascenzi \& Jagger 1979, Biggs et al. 1981, Tevini et al. 1981, Iwanzik et al. 1983, Teramura 1983, Tevini \& Iwanzik 1983, Jagger 1985, Häder et al. 1989, 1991, Häder 1993), and more especially, to microorganisms since they have no protective epidermal layer. Investigations on marine phytoplankton have indicated that photosynthetic productivity may decrease by 6 to $12 \%$ due to increased solar UV-B radiation under the Antarctic ozone hole (Smith et al. 1992). Persistence of this problem may lead to a number of ecological consequences including reduced biomass production, which will consequently affect the biological food web up to man, and reduced sink capacity for atmospheric carbon dioxide, which may augment the greenhouse effect.

Many cyanobacteria are adapted to rather low irradiances and are damaged or impaired by fluence rates 
exceeding a few percent of unfiltered solar radiation (Walsby 1968). Cyanobacteria have been reported to be responsible for up to $40 \%$ of the biomass of several aquatic ecoystems, and they contribute significantly to the nitrogen supply of eukaryotic algae and higher plants in aquatic and terrestrial ecosystems, respectively (Kumar \& Kumar 1988). In this paper, the effects of increased UV-B irradiation on energy transfer of the accessory pigments and photosynthesis in some filamentous freshwater and marine cyanobacteria are studied

\section{MATERIALS AND METHODS}

Oryanisms and culture conditions. Organisms used for this work include the freshwater benthic cyanobacteria Anabaena variabilis, Oscillatoria tenuis and Phormidium uncinatum (Baikal and Tübingen strains) obtained from the Göttingen (Germany) algal culture collection (Schlösser 1982), and 2 species of a marine planktonic cyanobacteria obtained from the Baltic Sea (Nodularia baltica and Nodularia harveyana). The freshwater organisms were grown on agar $(0.35 \%)$ C 6 mineral medium in $100 \mathrm{~mm}$ Petri dishes (Nultsch \& Häder 1974) covered with $200 \mathrm{~nm}$ pore membrane filters (SM 11307; Sartorius, Göttingen) and moistened with $5 \mathrm{ml} \mathrm{C} 6$ mineral solution. The marine organisms were grown in $\mathrm{BG} 10$ liquid medium in Erlenmeyer flasks. The cultures were kept under constant white light from mixed fluorescence lamps at $6 \mathrm{~W} \mathrm{~m}^{-2}$ in a temperature-controlled room $\left(20^{\circ} \mathrm{C}\right)$.

Measurements of absorption spectra. A homogenous $0.3 \%$ molten agar suspension of the organisms was prepared $\left(<40^{\circ} \mathrm{C}\right)$. Using a Pasteur micropipette the suspension was carefully filled, free of bubbles, into a quartz spectrophotometer cuvette (Hellma, Müllheim, Germany) with an optical pathlength of $10 \mathrm{~mm}$. The cuvette was closed with the lid and sealed with vaseline and parafilm. Absorption spectra were measured using a single beam spectrophotometer (DU-70, Beckman, Palo Alto, USA). The organisms were exposed to artificial UV radiation for various time intervals and absorption measurements taken after each irradiation period. To evaluate progressive bleaching, the reference spectrum (before irradiation) was subtracted from the subsequent spectra.

Fluorescence spectra. Fluorescence emission and excitation spectra were measured before and after various time intervals of UV-B irradiation in a quartz cuvette (2 $\mathrm{mm}$ thickness, $10 \mathrm{~mm}$ pathlength; Hellma) using a spectrofluorimeter (RF 5000, Shimadzu, Japan).

Photosynthetic gas exchange. Photosynthetic oxygen production was determined in a custom-made
Plexiglas cylinder with $20 \mathrm{~mm}$ inner diameter inside a thermostatic water jacket (RMT6, Dr Wobster GmbH. Lauda-Königshofen, Germany). The organisms were homogenized (20 s, $15000 \mathrm{rpm}$ ) to produce a mixture in C 6 solution. Aliquots of $7 \mathrm{ml}$ cell suspension were filled into the sample compartment and agitated with a magnetic stirrer. A Clark electrode (Yellow Springs Instruments, OH, USA) (Dubinsky et al. 1987) was inserted bubble free into the cell suspension and connected via a custom-made polarizer (Estabrook 1967) with a recorder (PM 8262, Phillips, The Netherlands). The system was calibrated with $10 \mathrm{mM}$ sodium dithionite for $0 \%$ oxygen saturation and for $100 \%$ by bubbling air through the suspension for $60 \mathrm{~min}$. The sample was irradiated with actinic white light produced from a $250 \mathrm{~W}$ slide projector with a $24 \mathrm{~V}$ quartz halogen bulb (Kindermann Universal, Wetzlar, Germany). The irradiance reaching the organisms was $160 \mathrm{~W} \mathrm{~m}^{-2}$. The organisms were exposed to UV radiation produced from a transilluminator (11-350-M, Bachofen, Reutlingen, Germany) (2.3 $\left.\mathrm{mW} \mathrm{cm}^{-2}\right)$ at regular time intervals of which $1.1 \mathrm{~mW} \mathrm{~cm}^{-2}$ fell into the UV-B range. This radiation was not intended to simulate solar radiation. However, the UV-B doses applied over the period of several hours are comparable to those encountered in nature.

\section{RESULTS}

In vivo absorption spectra measured for the Tübingen strain of Phormidium uncinatum showed absorp-

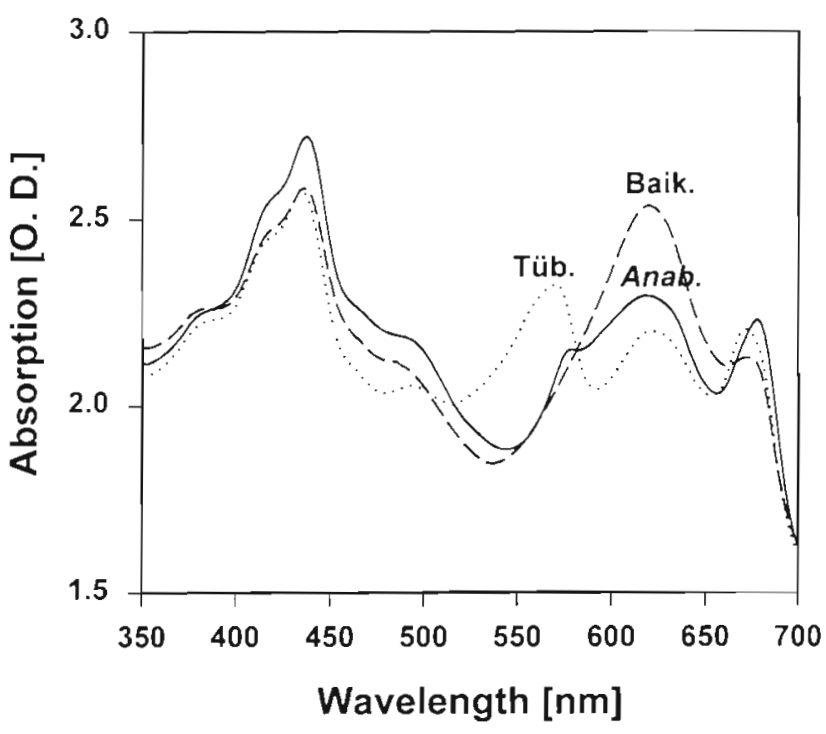

Fig. 1. Anabaena variabilis and Phormıdium uncinatum (Tübingen and Baikal strains). Absorption spectra showing absorption maxima corresponding to their photosynthetic pigments 


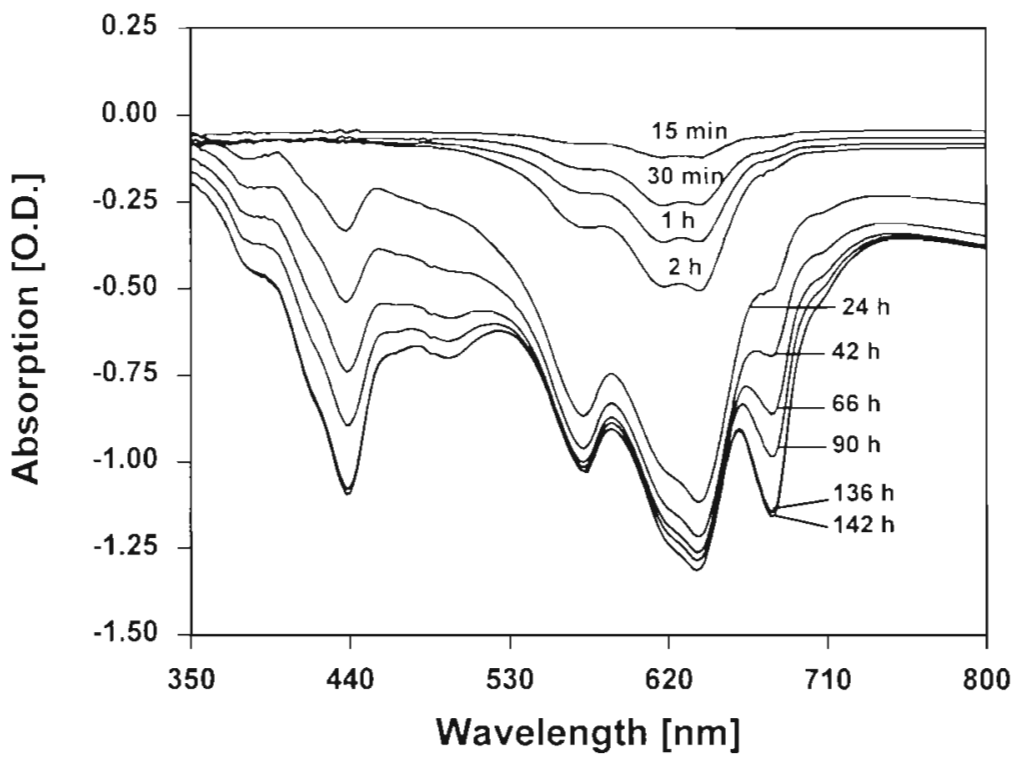

Fig. 2. Oscillatoria tenuis. Absorption difference spectra after increasing times of exposure to UV radiation obtained by subtracting the initial absorption spectrum of the unirradiated sample from each spectrum of the irradiated samples

tion maxima at 436,568,622 and $672 \mathrm{~nm}$ corresponding to the photosynthetic pigments chlorophyll a (Soret band), $\beta$-carotene, phycoerythrin, phycocyanin and chlorophyll a (red peak), respectively. For the Baikal strain absorption maxima occurred at 436, 492,620 and $672 \mathrm{~nm}$, without any phycoerythrin peak. Anabaena variabilis, however, had, in addition to the peaks of the Baikal strain of $P$. uncinatum, a shoulder at $581 \mathrm{~nm}$, corresponding to phycoerythrocyanin (Fig. 1). In addition there was a minor peak at $500 \mathrm{~nm}$ which probably corresponds to the absorption of a carotenoid. Oscillatoria tenuis showed all the peaks of the Tübingen strain of $P$. uncinatum, while the marine organisms Nodularia baltica and $N$. harveyana showed absorption peaks similar to those of the Baikal strain of $P$. uncinatum (data not shown).

When exposed to UV radiation from the transilluminator for various time intervals, a drastic decline in amplitudes of the peaks occurred. The reduction of amplitude of the peaks appeared to be fastest in the phycocyanin peaks, followed by the phycoerythrin peaks and then the carotenoids. Reduction in the chlorophyll peaks was comparatively low, as indicated by the absorption difference spectra (determined by subtracting the initial spectrum of the unirradiated control sample from each spectrum of the irradiated sample) (Fig. 2).
In order to determine the kinetics of the bleaching the irradiation was continued until the absorbance changes had reached an almost constant value. The rate of bleaching was determined by calculating the absorbance changes during exposure at prominent absorption maxima indicating the involvement of the major photosynthetic pigments; an example is shown in Fig. 3. A comparison of the times taken for $50 \%$ bleaching of the pigments to occur indicated that the $618 \mathrm{~nm}$ peak had the shortest half-life, followed by the $580 \mathrm{~nm}$ peak, the $490 \mathrm{~nm}$ peak, the $680 \mathrm{~nm}$ peak and finally the $438 \mathrm{~nm}$ peak. These experiments were not intended to mimic the effects of solar irradiation but to follow the bleaching kinetics of the photosynthetic pigments.

The fluorescence emission peak at $645 \mathrm{~nm}$, monitored at an excitation wavelength of $610 \mathrm{~nm}$, increased in amplitude up to $2 \mathrm{~h}$ irradiation, when the marine organisms, Nodularia baltica and N. harveyana, were exposed to UV radiation for increasing time intervals. This increase in amplitude was accompanied by a gradual shift of the peak to shorter wavelengths. Prolonged irradiation resulted in a decline in amplitude of the peak with a simultaneous shift to shorter wavelengths (Fig. 4). Similar results occurred in Phormidium uncinatum (Tübingen strain) where the excitation spectrum monitored at an emission wave-

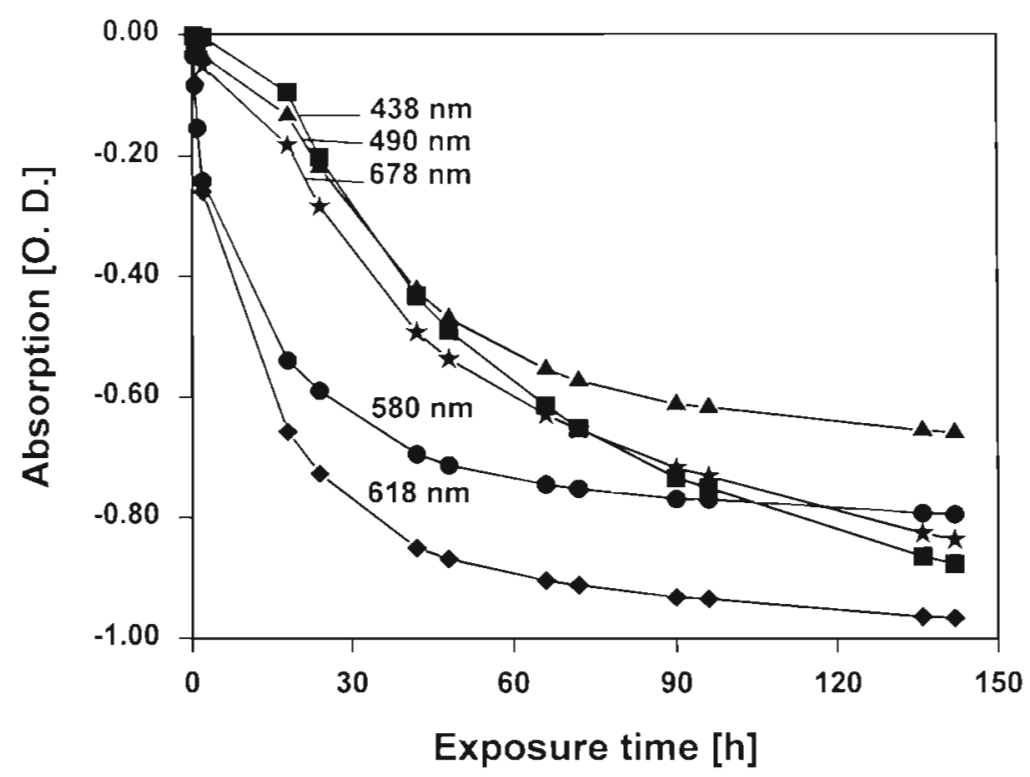

Fig. 3. Anabaena variabilis. Kinetics of bleaching of photosynthetic pigments after increasing times of exposure to artificial UV radiation 
length of $644 \mathrm{~nm}$ showed a single peak at $574 \mathrm{~nm}$, which increased after $1 \mathrm{~h}$ of UV irradiation and subsequently declined in amplitude (Donkor \& Häder 1991). An emission spectrum monitored at an excitation wavelength of $574 \mathrm{~nm}$ gave similar results. After $18 \mathrm{~h}$ of irradiation the fluorescence emission had declined almost to zero.

In the Baikal strain of Phormidium uncinatum a similar decline in the amplitudes was observed. An excitation spectrum measured at an emission wavelength of $680 \mathrm{~nm}$ had a small shoulder at $587 \mathrm{~nm}$ and a major peak at $620 \mathrm{~mm}$. Both of these, however, declined with increasing UV irradiation (Fig. 5). Wheir excited at wavelengths of 587 or $620 \mathrm{~nm}$, an emission peak at $644 \mathrm{~nm}$ was obtained in both instances. This peak also declined steadily with prolonged UV irradiation. In Anabaena variabilis and Oscillatoria tenuis similar trends were observed.

Photosynthetic oxygen production was measured in the various organisms at an irradiance of $160 \mathrm{~W} \mathrm{~m}^{-2}$. The photosynthetic rate was measured in nmol of oxygen produced per $g$ fresh weight of organisms per minute. In Phormidium uncinatum (Tübingen strain) the initial photosynthetic rate was $22.17 \mathrm{nmol} \mathrm{g}^{-1} \mathrm{~min}^{-1}$. After $5 \mathrm{~min} \mathrm{UV}$ radiation the rate reduced to $11.36 \mathrm{nmol} \mathrm{g}^{-1} \mathrm{~min}^{-1}$. Further irradiation reduced the photosynthetic oxygen production

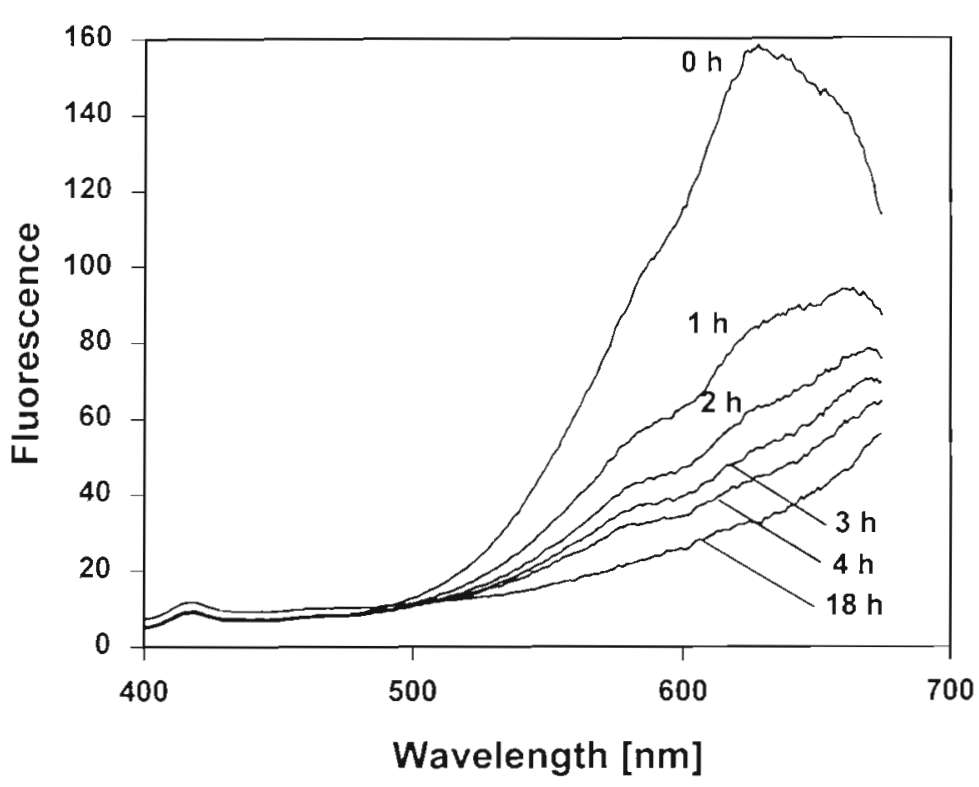

Fig. 5. Phormidium uncinatum (Baikal strain). Fluorescence excitation spectra monitored at an emission wavelength of $680 \mathrm{~nm}$ as a function of UV exposure. Slit width for both excitation and emission was $10 \mathrm{~nm}$ very drastically, and after 12 min irradiation the rate reached zero, after which it continued to decrease further until it became relatively constant after $30 \mathrm{~min}$ irradiation. The rate of respiration, measured in darkness, was also reduced drastically with increasing UV irradiation, and became relatively constant after 45 min of irradiation (Fig. 6). In Oscillatoria tenuis similar trends in photosynthetic gaseous exchange occurred, the rate of oxygen production reaching zero after $15 \mathrm{~min}$.

Although the photosynthetic rates were relatively higher in the Baikal strain of Phormidium uncinatum and Anabaena variabilis, a similar dramatic decline in rates occurred even after $5 \mathrm{~min}$ irradiation. In the Baikal strain of $P$. uncinatum, the rate of photosynthesis reached zero after about 22 min of irradiation, while that of $A$. variabilis reached zero after $20 \mathrm{~min}$.

\section{DISCUSSION}

Absorption difference spectra indicate that photosynthetic pigments are affected by UV-B radiation. In cyanobacteria, photobleaching has been shown to be induced by visible light (Nultsch \& Agel 1986, Häder 1988). However, the present results indicated that it can also be induced by exclusive UV radiation. The kinetic analyses of the bleaching shows that 


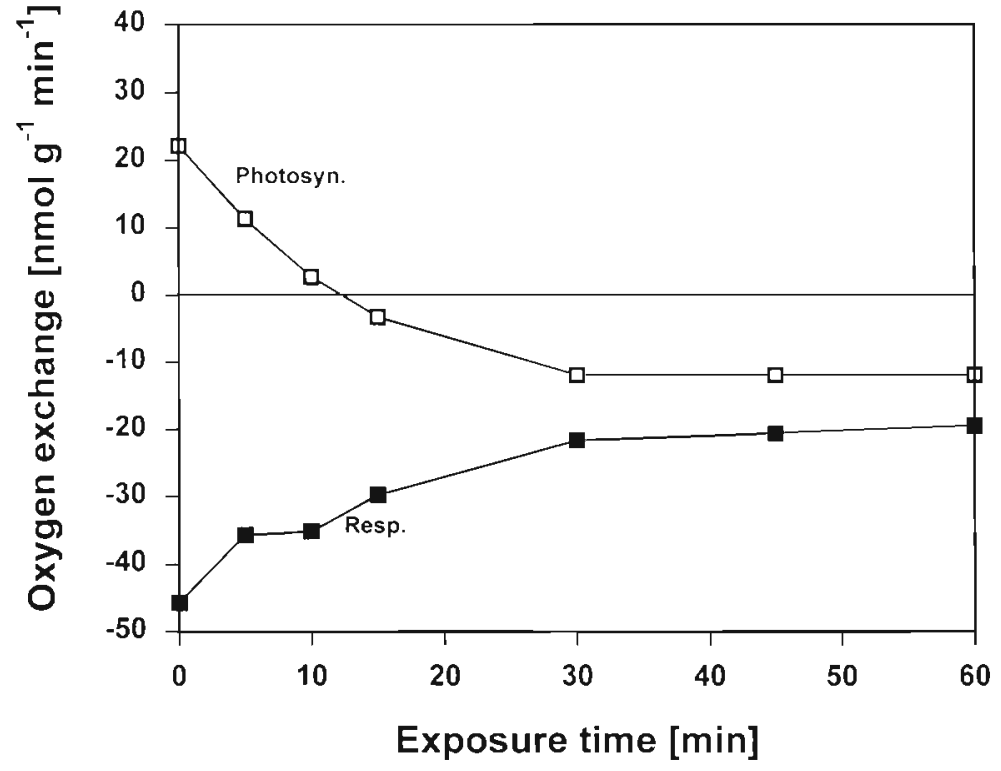

Fig. 6. Phormidium uncinatum (Tübingen strain). Photosynthetic oxygen production $(\square)$ and dark respiration ( $\square$ ) after exposure to increasing times of UV irradiation

the accessory pigments, the phycobilins, were bleached first, indicating that the major accessory pigments of cyanobacteria (as well as cryptophyceae and red algae) are affected much more than the pigments in other algal groups. Next the carotenoids, which serve the dual function of photoprotection and energy transduction to the chlorophyll reaction centers, are damaged, while chlorophyll is the most resistant to bleaching. This is in accordance with data obtained for some members of the cryptophyceae (Häder \& Häder 1990, Zündorf \& Häder 1991).

Most of the excitation energy absorbed by the phycobilins is passed to chlorophyll a. However, since the phycobilins show a considerable autofluorescence even in control samples the energy transfer is less than $100 \%$. These losses increase during UV-B exposure: during the first $2 \mathrm{~h}$ of UV irradiation in the two species of Nodularia the fluorescence emission spectrum monitored at an excitation wavelength of $610 \mathrm{~nm}$ showed an increase in amplitude of the peak, indicating a decrease in energy transfer to photosystem I, and a simultaneous shift to shorter wavelengths. Prolonged irradiation further shifted the peak to shorter wavelengths while the amplitude decreased drastically. This was also observed in Phormidium uncinatum (Tübingen strain). The increase in amplitude signals a dramatic loss in effectivity of energy transfer to the photosynthetic reaction center so that more energy is wasted in the form of fluorescence. The remarkable shift in emission wavelength could be explained by the results of Mörschel \& Wehrmeyer (1977), who demonstrated that multiple forms of phycoerythrin could be separated by isoelectric focusing in Cryptomonas maculata. One of these forms absorbed at $545 \mathrm{~nm}$ (type I), another form at $555 \mathrm{~nm}$ (type II), and others from 565 to $568 \mathrm{~nm}$ (type III). The sequential appearance of these forms during exposure to UV-B irradiation indicates that these charged isomers may be degradation products of an initial form (Mörschel \& Wehrmeyer 1975). Exposure to UV radiation first causes the high molecular mass aggregates to break down into hexamers $(\alpha \beta)_{6}$, which then disintegrate into trimers $(\alpha \beta)_{3}$ and eventually to monomers ( $\alpha \beta$ ) (Mörschel et al. 1980, Glazer 1982). Similar shifts were observed in the phycocyanin emission peaks of the Tübingen strain of $P$. uncinatum. This also confirms the occurrence of multiple charged isomers found in the phycocyanins of a Chroomonas species (Mörschel \& Wehrmeyer 1975).

Photosynthetic oxygen production was drastically affected by artificial UV-B radiation in all the organisms investigated. The inhibitory doses are comparable to natural solar UV radiation while for practical reasons the irradiances were chosen to be higher than in natural sunlight. This inhibition of photosynthesis is even more rapid than the effect on motility or orientation (Donkor \& Häder 1991), and since absorption spectroscopy shows massive bleaching only after longer exposure times, it could be possible that structural changes within the photosynthetic apparatus were induced by short exposure times which affected the energy transfer within the antenna complex, while UV-induced photobleaching occurred only after prolonged irradiation. This confirms observations by Häberlein \& Häder (1992) on the freshwater flagellate Cryptomonas and by Schäfer et al. (1993) on the green dinoflagellate Gymnodinium. Exposure of the organisms to solar radiation also showed similar inhibition of photosynthesis (data not shown), indicating that solar UV-B radiation at ambient levels was effective in causing structural changes in the photosynthetic apparatus leading to inhibition of photosynthesis. Such structural changes in the photosynthetic apparatus have also been detected in higher plants after exposure to solar radiation (Renger et al. 1989, Tevini et al. 1989). Thus, UV-B radiation has been found to damage the reaction center of photosystem II and to cause structural changes in the D1 and D2 proteins in the thylakoid membranes. In addition, the radiation causes a decrease in the lipid content, affects nucleic acids and reduces the protein content, which affects enzyme activity and production, as shown in some marine diatoms and cyanobacteria (Döhler et al. 1987). 


\section{CONCLUSION}

The cyanobacteria used in this study were all sensitive to UV radiation. The phycobilins in particular were more affected than the main photosynthetic pigments of other algal groups. This high sensitivity supports the concern about increases in solar UV-B radiation which may stress phytoplankton organisms (Häder et al. 1991). Recently, solar UV-B radiation has been found to penetrate far deeper into the euphotic zone than considered before, indicating a substantial hazard (Gieskes \& Kraay 1990, Smith et al. 1992). Since no phytoplankton organism has been found to orient within the water column with respect to ultraviolet radiation (Häder \& Worrest 1991), an increase in solar Uv-B radiation will not causc tho organisms to move to lower levels (with less UV-B), but rather increase the UV-B stress.

Acknowledgements. This work was financially supported by European Community (EV5V-CT91-0026) and BayFORKLIM (DIII 1) grants to D.-P.H

\section{LITERATURE CITED}

Ascenzi JM, Jagger J (1979) Ultraviolet action spectrum $(238-405 \mathrm{~nm})$ for inhibition of glycine uptake in $E$. coli. Photochem Photobiol 30:661-666

Biggs RH, Kossuth SV, Teramura AH (1981) Response of 19 cultivars of soybeans to ultraviolet-B irradiance. Physiol Plant 53:19-26

Döhler G, Worrest RC, Biemann I, Zink J (1987) Photosynthetic ${ }^{14} \mathrm{CO}_{2}$ fixation and ${ }^{15} \mathrm{~N}$-ammonia assimilation during UV-B radiation of Lithodesmium variabile. Physiol Plant 70:511-515

Donkor V. Häder DP (1991) Effects of solar and ultraviolet radiation on motility, photomovement and pigmentation in filamentous, gliding cyanobacteria. FEMS Microbiol Ecol 86: $159-168$

Dubinsky Z, Falkowski PG, Post AF, van Hes UM (1987) A system for measuring phytoplankton photosynthesis in a defined light field with an oxygen electrode. J Plankton Res 9:607-612

Estabrook RW (1967) Mitochondrial respiratory control and the polarographic measurement of $\mathrm{ADP}: \mathrm{O}$ ratios. In: Estabrook RW, Pullmann ME (eds) Methods in enzymology, Vol X. Academic Press, New York, p 41-47

Gieskes WC, Kraay GW (1990) Transmission of ultraviolet light in the Weddell sea: report on the first measurement made in Antarctic. Biomass Newsl 12:12-14

Glazer AN (1982) Phycobilisomes: structure and dynamıcs. Ann Rev Microbiol 36:173-198

Häberlein A, Häder DP (1992) UV effects on photosynthetic oxygen production and chromoprotein composition in a freshwater flagellate Cryptomonas. Acta Protozool 31: $85-92$

Häder DP (1988) Ecological consequences of photomovement in microorganisms. J Photochem Photobiol B Biol 1: $385-414$
Häder DP (1993) Effects of enhanced solar ultraviolet radiation on aquatic ecosystems. In: Tevini M (ed) UV-B radiation and ozone depletion. Effects on humans, animals, plants, microorganisms and materials. Lewis Publ, Boca Raton, p 155-192

Häder DP, Häder M (1990) Effects of solar radiation on motility, photomovement and pigmentation in two strains of the cyanobacterium Phormidium uncinatum. Acta Protozool 29:291-303

Häder DP, Worrest RC (1991) Effects of enhanced solar ultraviolet radiation on aquatic ecosystems. Photochem Photobiol 53:717-725

Häder DP, Worrest RC, Kumar HD (1989) Aquatic ecosystems. UNEP Environmental Effects Panel Report, Nairobi, p $39-48$

Häder DP, Worrest RC, Kumar HD (1991) Aquatic ecosystems. UNEP Environmental Effects Panel Report, Nairobi, p 33-40

Iwanzik W, Tevini $M$, Dohnt $G$, Voss $M$, Weiss $W$, Gräber $P$, Renger G (1983) Action of UV-B radiation on photosynthetic primary reaction in spinach chloroplasts. Physiol Plant 58:401-407

Jagger J (1985) Solar-UV actions on living cells. Praeger Publications, New York, p 202

Kumar A, Kumar HD (1988) Nitrogen fixation by blue-green algae. In: Sen SP (ed) Plant physiology research. 1st International Congress of Plant Physiology, New Society for Plant Physiology and Biochemistry, New Delhi, p 15-22

Mörschel E, Koller KP, Wehrmeyer W (1980) Biliprotein assembly in the disc-shaped phycobilisomes of Rhodella violacea: electron microscopical and biochemical analyses of C-phycocyanin and allophycocyanin aggregates. Arch Microbiol 125:43-51

Mörschel E, Wehrmeyer W (1975) Cryptomonad biliprotein: phycocyanin-645 from a Chroomonas species. Arch Microbiol 105:153-158

Mörschel E, Wehrmever W (1977) Multiple forms of phycoerythrin-545 from Cryptomonas maculata. Arch Microbiol 113:83-89

Nultsch W. Agel G (1986) Fluence rate and wavelength dependence of photobleaching in the cyanobacterium Anabaena variabilis. Arch Microbiol 144:268-271

Nultsch W, Häder DP (1974) Über die Rolle beiden Photosysteme in der Photophobotaxis von Phormidium uncinatum. Ber Dtsch Bot Ges 87:83-92

Renger G, Völker M, Eckert HJ, Fromme R, Hohm-Veit S, Graber P (1989) On the mechanisms of photosystem II detenoration by UV-B irradiation. J Photochem Photobiol B Biol 2:123-132

Schäfer J, Sebastian C, Häder DP (1993) Effects of solar radiation on motility, orientation, pigmentation and photosynthesis in a green dinoflagellate Gynnodinium. Acta Protozool 33:59-65

Schlosser UG (1982) Sammlung von Algenkulturen. Ber Dtsch Bot Ges 9:181-276

Setlow RB (1974) The wavelength in sunlight effective in producing skin cancer: theoretical analysis. Proc Natl Acad Sci USA 7 1:3363-3369

Smith RC, Prezelin BB, Baker KS, Bidigare RR, Boucher NP, Coley T, Karentz D, MacIntyre S, Matlick HA, Menzies D, Ondrusek M, Wan Z, Waters KJ (1992) Ozone depletion: ultraviolet radiation and phytoplankton biology in Antarctic waters. Science 255:952-959

Teramura AH (1983) Effects of ultraviolet-B radiation on the growth and yseld of crop plants. Physiol Plant 58:415-427

Tevinu M. Häder DP (1987) General pholobiology. Pergamon Press, New York 
Tevini M, Iwanzik W (1983) Inhibition of photosynthetic activity by UV-B radiation in radish seedlings. Physiol Plant 58:395-400

Tevini M, Iwanzik W. Thoma U (1981) Some effect of enhanced UV-B irradiation on the growth and composition of plants. Planta 153:388-394

Tevini $M$, Teramura AH, Kulandaivelu G, Caldwell MM,

Responsible Subject Editor: T. H. Blackburn, Aarhus,

Denmark
Björn LO (1989) Terrestrial plants. UNEP Environmental Effects Panel Report, Nairobi, p 25-37

Walsby AE (1968) Mucilage secretion and the movements of blue-green algae. Protoplasma 65:223-238

Zündorf I, Häder DP (1991) Biochemical and spectroscopic analysis of UV effects in the marine flagellate Cryptomonas maculata. Arch Microbiol 156:405-411

Manuscript first recerved: June 12,1996

Revised version accepted: August 21, 1996 